\title{
Mobile Learning Approach in Higher Education Institutes (HEIS): Insights beyond the Acceptance Model of Technology
}

\author{
Abdelbaset Queiri ${ }^{1}$, Araby Madbouly ${ }^{2}$ \\ ${ }^{1}$ Management and Tourism Department, Oman Tourism College, Sultanate of Oman \\ ${ }^{2}$ Business and Accounting Department, Muscat College, Sultanate of Oman \\ abdelbaset.queiri@otc.edu.om, araby@muscatcollege.edu.om
}

\begin{abstract}
The purpose of the study is to develop a framework beyond the technology acceptance model (TAM) whereby the study aims to understand the slow adoption of M-learning approach in HEIs. For this purpose, this study carries out an extensive review of the literature in order to design a conceptual framework to investigate how to enhance the utilization of this technology among lecturers and learners/students. The investigation was carried out using a deductive approach to examine the proposed hypothesizes. The findings from this study suggest a wide range of factors such as cultural dimension (i.e. uncertainty avoidance), psychological factors (i.e. perceived risk, self-efficacy) technical skills (i.e. digital literacy). These factors are regarded to be relevant towards enhancing the utilization of M-learning in HEIs. This study has the originality of ideas by providing insights into M-learning utilization beyond the conventional TAM. These identified factors require to be substantiated in this context.
\end{abstract}

Keywords: M-learning, TAM, adoption of M-learning, HEIs

\section{Introduction}

In the digital age and as part of the pedagogical shift, Saudi Arabia is shifting from the teacher-centered approach to be more focusing on the learner-centered approach (Nassuora, 2012). With awareness to the need of such shift among younger generation and with the availability of sound technological infrastructure (i.e. smart devices, portable devices, wireless and etc..), Saudi Arabia Higher Education sector is seen a heavy investment, in order to promote learning and teaching approach that meet the requirement of digital age (AlShehri, 2009). Particularly for the younger generation in Saudi Arabia who is assumed to be technologically savvy and digitally connected. For this purpose, Saudi government had proposed mobile learning approach (M-Learning) with the aim of; 1) assisting all students from different social-economic levels to take part of the on-going educational process through enabling citizens to access seminars, training and lectures using their own devices, regardless of their places, 2) M-learning sought to provide lifelong experience of learning by enhancing the students 'engagement, performance and collaboration, in other words, M-Learning will create the kind of highly situated personal (Liu \& Han, 2010). In the same vein, several Universities in Saudi Arabia had already responded to the Saudi government and the Ministry of Higher Education initiatives to adopt M-Learning approach. For instance, King Saud University enabled its students to communicate with each other and with the university from students' own platform, to respond to the students' inquiries and share the information among each other (Almutairy \& Dimitriadi, 2014). Also, King Khalid University introduced synchronized virtual blackboard, whereby students are informed about university announcement while using social media websites.

Moreover, many other Saudi Universities signed a cooperation agreement with the famous international institute to implement M-Learning approach (Al-Shehri, 2009). Despite the initiatives to adopt M-Learning in Saudi Arabian Universities and the availability of the affordable and good Mobile phone infrastructure (Narayanasamy \& Mohamed, 2013). Yet, the utilization of the M-Learning approach to the full potential is not attained at Universities level. Additionally, the use of M-learning in Saudi Arabia Universities is in its infancy stage. In 2015, Saudi Arabia M-Learning approach was considered at the developmental stages and the benefits of such an approach still have high potential (Almutairy \& Dimitriadi, 2014). Many Universities are using M-Learning for the purpose of announcement and communication with students. For M-Learning successful transition with acquiring all the potential benefits, there is a need more than ever to adopt MLearning in a teaching setting, in other words, using M-learning at an advanced level to deliver lectures. Several studies have focused on the factors influencing the acceptance of M-Learning approach among Saudi Arabia students, in order to understand the modest adoption of M-learning. 
Majority of these studies have relied on the so-called Technology Acceptance Model (TAM) to fulfil such purpose. Other researchers turned the focus on the unified theory of acceptance and use of Technology model (UTAUT Model) to investigate the relevant factors which lead to the slow adoption of M-Learning in Saudi Arabian context, as in (Hujran, Lozi \& Debei, 2014; Aljuaid, Alzahrani \& Islam, 2014; Nassouora, 2012; Despite the superiority of UTAUT model over TAM, in terms of identifying more factors, such as social influence and facilitating conditions. Both models utilized in the aforementioned studies share similar factors such as performance expectancy and effort expectancy, which are regarded interchangeably as perceived usefulness and perceived ease of use in TAM. Also, some of these studies merely used the perceived usefulness and ease of use to understand the issue at hand. The use of the two models at the current stage, limit our understanding of the M-learning utilization and its challenges in the context of Saudi Arabia. There is a need for an expansion of these two theoretical models to increase the understanding of the modest adoption of Mlearning in context of Saudi Arabian Universities. Moreover, these two models and the associated studies are specifically tailored for students in Saudi Arabia context, although lecturers are part of the process, nevertheless, a scant attempt has been located the focus on the issue from the lecturers' perspectives (Reference).

There is a need to deepen the studies to understand the mechanism of M-learning utilization and adoption among lecturers. This requires going beyond TAM and UTAUT models and incorporating other novel factors, such as; digital literacy (basic ICT literacy and mobile ICT literacy), self-efficacy (abilities), ICT anxiety, perceived risk (social and financial risk), cultural dimension (uncertainty avoidance), social support (management, peer and student supports). These factors have not been substantiated in the context of Saudi Arabia, nor how they interact with each other investigated. Moreover, the traditional factors of perceived usefulness and ease of use have been incorporated as suggested by the theory of technology acceptance. On the other hand, several other researches have concentrated on the challenges of the use of M-Learning in Saudi Arabia context; many were generic. These proposed challenges were either assessed subjectively or through descriptive studies. To fulfil the scientific inquiries, there is a need to develop a theoretical model and framework which is better than subjective opinions. With this said, there is a need of addressing the factors that inhibit the full adoption of M-Learning from lecturer perspective. This will provide the opportunities of transforming the lecturers to a highly situated personal, which may result in better engagement, collaboration and paying attention to provide education to different social economic classes.

\section{Literature Review}

Underpinning Theories: This study utilizes several core theories to assist in developing, the theoretical framework. However, this study will also enrich the theoretical discussion by incorporating, other secondary theories and expanding the core one. These theories will serve as input of identifying the relevant factors that will be the subject of investigation. Furthermore, these theories and the on-going literature of review studies will specify the reasons for selecting such factors over the others in the context of Saudi Arabia.

The Reasoned Action Theory: Following the work of Fishbein \& Ajzen in 1975, the engagement in a certain behavior or in particular course of action is best predicted by the behavioral intention to perform such action. The behavioral intention since then was regarded to be a substitute for the actual behavior. With this said, it becomes more feasible to measure the behavioral intention to utilize M-learning approach rather than measuring the actual utilization or adoption. The actual adoption may be subjected to the availability of external resources and opportunities. Therefore, it becomes of first priority to measure the readiness and the intention to utilize.

Planned behavioral Theory: As a result of the development of reasoned action theory, Ajzen in 1991, argued that the despite the intention intensity of performing a course of action, however, the intensity will be attenuated when it is compared to the ability or the confidence in engaging into that specific course of action. Such ability was referred to the perceived behavioral control. The latter term and its definition were not devoid from the debate, however, the term was widely used to indicate self-efficacy, and confidence and ability to strengthening the intention's intensity. Nevertheless, with Saudi Arabia scores high in this dimension, the effect of uncertainty avoidance has received little attention be the reason for low utilization or slow adoption towards the M-learning approach. 
Technology Acceptance Model: In 1989, Davis introduced the technology acceptance model (TAM). This model was originally derived from the aforementioned theories; reasoned action and planned behavioral theories. From the perspective that subjective norms, beliefs or attitudes affect behavioral intention, TAM model specifies two beliefs dimensions, which they are perceived ease of use and perceived usefulness which in return will influence the behavioral intention to use the technology. Thereafter, the TAM model has been extensively used to measure the behavioral intention to use technology, such as; distance learning, mobile banking, mobile learning and other innovativeness technological solutions.

Unified Theory of Acceptance and Use of Technology: In 2003, Vankatesh expanded the TAM, through incorporating the connotation of social cognitive principles (Venkatesh et al., 2003). His model composes of performance and effort expectancies, which they are regarded to be equal to perceived usefulness and ease of use. In addition to this, social influences and facilitating conditions were part of the newly introduced factors. This study uses the social influences and facilitating conditions in different perspective, both terms will be used as a moderator in terms of social organizational support. This moderator suggests that the behavioral intention to utilize M-learning among lecturers will be subjected to the perceived support received from university, colleagues and students. Then only, the utilization of M-learning approach will be adopted with the availability of perceived ease of use and perceived usefulness.

Hofstede's Cultural Dimension: Hofstede set forth broad cultural dimensions; collectivism vs. individualism, masculinity vs. femininity, uncertainty avoidance, long-term orientation, power distance and indulgence. In this study, the focus will be given to uncertainty avoidance, since it is related to the concept of the averting unexpected events or resistance to deal with the ambiguous. Furthermore, uncertainty avoidance deals with acceptance of the new and the unknown. People with low uncertainty avoidance are comfortable and open to change and more tolerant to accept the risk and have willing to adopt a new structure or system. The dimension has been traditionally incorporated into the context of technology adoption and reported to have an impact on the acceptance of technology (Mulaomerovic \& Trappey, 2013).

Previous Studies of M-Learning Approach in Saudi Arabia: The extensive review of the literature revealed several studies conducted in the context of Saudi Arabia pertaining the adoption and utilization of M-learning approach in different settings (i.e. Universities and high schools). Nassuora (2012) surveyed around 80 students at Al-Faisal University to determine the level of acceptance of M-learning approach. In his study the UTAUT Model has been empirically investigated. Despite the study's initiative to empirically investigate the dimensions of UTAUT Model, the downside of this study was the small number of sample size along with the focus on a single private university to measure the acceptance level among students. Clearly, the use of a quantitative case study may limit the generalizability of findings to some extent to other universities in Saudi Arabia. Al-Hujran et al. (2014) similarly used the UTAUT model to investigate the behavioural intention to use M-learning approach in Saudi Arabia. The sample consisted of 215 students originated from Al-Faisal University. Despite the inclusion of more respondents, both studies confined itself to Al-Faisal University. Another study conducted in Saudi Arabia to investigate the adoption of M-learning approach was developed by (Narayanasamy \& Mohamed, 2013). This study expanded the number of surveyed participants to 300, solely to be drawn from Jazan University.

This study provides a mere descriptive statistic on the awareness of mobile technologies, application, advantages and limitation. Furthermore, the study inquires on expectation of M-learning. These descriptive results were driven by the students' perception. Despite the large portion of sample size, this study confined itself to the descriptive analysis and the knowledge of what caused the adoption among users could not be established. Similarly, measured the interest of Students into M-learning approach in addition, the students were asked to rank the advantages and disadvantages associated with the use of M-learning approach. Also, Almutairy \& Dimitriadi (2014) descriptively assessed the readiness of Saudi Arabian Students to use Mlearning approach. Moreover, the literature enriched us with several subjective studies that were developed to address the challenges and prospects of M-learning approach in the context of Saudi Arabia. In the study of Alkhalaf (2014), the challenges were subjectively argued towards the adoption of M-learning at High School. The subjective study does not fulfil the scientific inquiry extended the TAM model, to incorporate other factors such as ICT anxiety and perceived innovativeness in order to measure the intention to use. 
This study offers a hint for researchers to further expand the theoretical framework applied in Saudi Arabia and to incorporate other factors. Unlike the aforementioned studies, this study will give an insight of the utilization of M-learning from the perspective of lecturers, whereby several relevant dimensions will be the focus of this study, which goes beyond the conventional models (i.e. TAM and UTAUT). There is a dearth of studies on M-learning adoption from lecturers' perspective in Saudi Arabia. Exceptional, the study conducted by Aljuaid et al. (2014) who investigated the readiness of mobile learning among lecturers, nevertheless, the study has focused on two dimensions of the TAM model; perceived ease of use and perceived usefulness.

\section{Proposed Theoretical Framework}

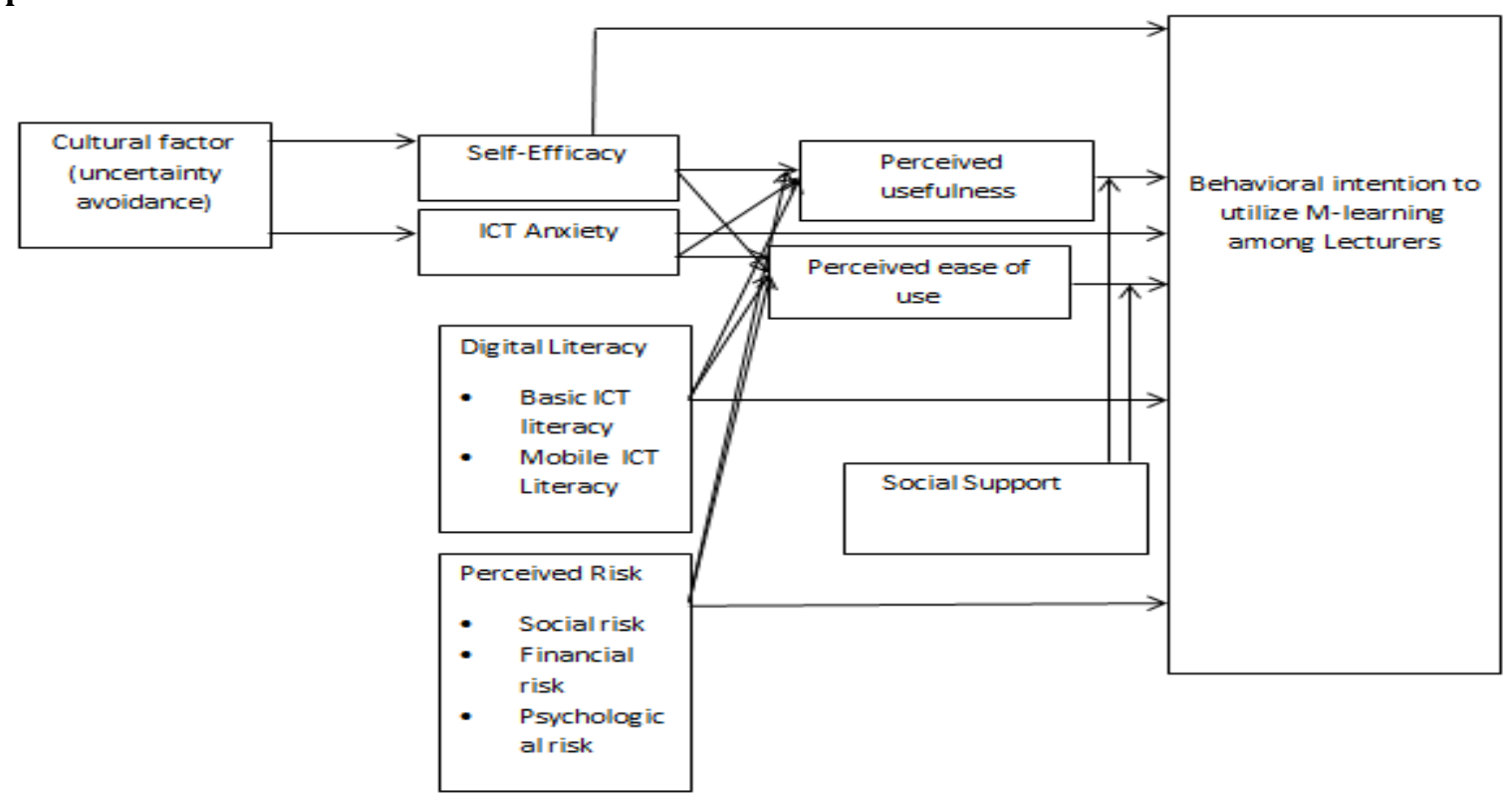

\section{Methodology}

Research Strategy: This study will use a survey research strategy. Such a choice is guided by the proposed research questions. With the use of a survey, descriptive results and hypothesizes testing will be possible, since survey study allows to gather quantitative data. Furthermore, the survey study will assist in making an inferential statistical to reject or accept hypothesizes.

Population and Sampling Procedure: The target population of study will be the lecturers in Saudi Arabian Universities. Additionally, this study will have a target population of the knowledgeable lecturers who already have experience or knowledge in using M-learning approach. The rationale of choosing such a population is due to the nature of the questionnaire that requires from respondents to be fully aware of M-learning practices, advantages and challenges. Therefore, the nonprobability sampling method, in particular purposive - convenient sampling procedure is deemed to be the most appropriate for this study. This is because, the targeted respondents are selected based on certain criteria (to fulfil the purpose of research and solicit the most accurate answers), whereby the lecturers require to have previous knowledge and currently using $\mathrm{M}$ learning approach at any level. Additionally, convenient sampling is chosen due to the freedom of participation and there is no particular sampling frame to guide the choice of respondents randomly.

Operationalization of Key Variables: This study will use a set of questionnaires and this questionnaire will be adopted from other studies. In a sense, the factors will be slightly or largely modified to reflect the particular interest of the study along with consideration of the context of the study. Unlike other studies which relied on a qualitative approach. This study will develop items to reflect the factors as depicted in the framework. The development of the questionnaire will be guided by an extensive review of the literature, validating the items and other process which will ensure the measurement effectiveness in terms of reliabilities and validities. Several types of validities will be used while constructing a questionnaire, such as; 
face and content validities that will be achieved through experts' judgment of the developed items and other extensive review of the literature.

Data Analysis: This study relies on the two-step approach suggested by Anderson and Gerbing (1988) to perform the analysis stage, measurement and structural models. The measurement model aims to validate the constructs using confirmatory factor analysis (CFA), common method variance and invariance analysis. In addition, the structural model will assist in providing statistical inference on the proposed hypothesizes. For this purpose, Smart PLS3 will be used to conduct this analysis.

\section{Conclusion}

Technology acceptance model (TAM) has extensively used in the context of Saudi Arabia. Some of the studies were subjective in nature, others used the TAM model in terms of commonly used two dimensions. This study suggests the expansion of TAM to comprehensively comprehend the reasons behind the slow adoption of Mlearning. The researcher developed a theoretical framework based on extensive review of the literature and found that there are a number of antecedents which are required to be investigated. The study puts this finding into such perspective; cultural factor, psychological factor and technical factor. The study also concluded that these factors interact with each other in a certain way to increase our understanding of the mechanism of M-learning adoption.

\section{References}

Ajzen, I. (1991). The theory of planned behaviour. Organizational behaviour and human decision processes, 50(2), 179-211.

Aljuaid, N. M. F., Alzahrani, M. A. R. \& Islam, A. Y. M. (2014). Assessing mobile learning readiness in Saudi Arabia higher education: An empirical study. Malaysian Online Journal of Educational Technology, 2(2), 1-14.

Alkhalaf, A. (2014). Identifying mobile learning challenges at male high schools in Saudi Arabia from the teachers' point of view. International Journal of Learning and Teaching, 6(1), 30-37.

Almutairy, S., Davies, T. \& Dimitriadi, Y. (2014, November). The readiness of applying m-learning among Saudi Arabian students at higher education. In 2014 International conference on interactive mobile communication technologies and learning (IMCL2014) (pp. 102-106). IEEE.

Al-Shehri, S. (2009). An outlook on future mobile learning in Saudi Arabia. Q Science Proceedings, (12th World Conference on Mobile and Contextual Learning [m Learn 2013), 9.

Anderson, J. C. \& Gerbing, D. W. (1988). Structural equation modelling in practice: A review and recommended two-step approach. Psychological bulletin, 103(3), 411.

Davis, F. D., Bagozzi, R. P. \& Warshaw, P. R. (1989). User acceptance of computer technology: a comparison of two theoretical models. Management science, 35(8), 982-1003.

Fishbein, M. \& Ajzen, I. (1975). Belief, attitude, intention and behaviour: An introduction to theory and research.

Liu, Y., Han, S. \& Li, H. (2010). Understanding the factors driving m-learning adoption: a literature review. Campus-Wide Information Systems, 27(4), 210-226.

Al-Hujran, O., Al-Lozi, E. \& Al-Debei, M. M. (2014). Get Ready to Mobile Learning": Examining Factors Affecting College Students' Behavioural Intentions to Use M-Learning in Saudi Arabia. Jordan Journal of Business Administration, 10(1), 111-128.

Mulaomerovic, E. \& Trappey, C. V. (2013, June). The role of cultural dimensions in the acceptance of retail innovations. In Proceedings of the Management, Knowledge and Learning International Conference.

Narayanasamy, F. S. \& Mohamed, J. B. K. (2013). Adaptation of mobile learning in higher educational institutions of Saudi Arabia. International Journal of Computer Applications, 69(6).

Nassuora, A. B. (2012). Students acceptance of mobile learning for higher education in Saudi Arabia. American Academic \& Scholarly Research Journal, 4(2), 24-30.

Venkatesh, V., Morris, M. G., Davis, G. B. \& Davis, F. D. (2003). User acceptance of information technology: Toward a unified view. MIS Quarterly, 425-478. 